\title{
Benedito Nunes, idealizador e professor do Curso de Filosofia da Universidade Federal do Pará
}

\author{
Benedito Nunes, creator and professor of the \\ Philosophy Course at the Federal University of Pará \\ Elizabeth Assis Dias \\ https://orcid.org/0000-0003-0951-6313 - E-mail: elizabethadias28@gmail.com
}

\section{RESUMO}

O objetivo do presente artigo é prestar uma homenagem à memória de Benedito Nunes, tendo em vista os dez anos de seu falecimento. Nossa pretensão é destacar o seu papel na criação do curso de Filosofia da Universidade Federal do Pará, seu empenho para a composição e formação do corpo docente do curso, bem como para o seu crescimento e qualidade. Iremos também, rememorar alguns aspectos de sua atuação, enquanto professor do curso e formador das novas gerações, que o sucederam.

Palavras-chaves: Filosofia. Legado. Curso de Filosofia. Ensino de Filosofia.

\begin{abstract}
The objective of this paper is to pay homage to the memory of Benedito Nunes, considering the ten years of his death. Our intention is to highlight your role in the creation of the Philosophy course at the Federal University of Pará, your commitment to the composition and training of the course's faculty, as well as to its growth and quality. We will also recall some aspects of his performance as a teacher of the course and trainer of the new generations that followed him.
\end{abstract}

Keywords: Philosophy. Legacy. Philosophy course. Philosophy teaching. 


\section{Introdução}

O ano de 2021 marca o décimo aniversário de morte de Benedito Nunes. Trata-se, não apenas de um momento triste, cujo aniversário nos trás a memória sua partida e a lacuna que deixou no meio acadêmico, mas também, de uma oportunidade para refletirmos sobre seu legado, evidenciarmos suas realizações e o seu valor enquanto pensador dedicado ao estudo da filosofia e da literatura.

Benedito Nunes, conhecido nacional e internacionalmente, escolheu Belém, ou melhor, sua residência em Belém na travessa Estrela, como espaço ideal para produzir suas reflexões. Lugar que ele reputava como sendo de "voluntária reclusão" dentro da outrora "cidade das mangueiras" e com o qual criou raízes, que lhe entrelaçaram (NUNES, 2009, p. 91). Tinha consciência que se pode pensar e escrever em qualquer lugar desde que houvesse as mínimas condições para tal. E para ele bastava o papel e a caneta e, também, uma boa biblioteca, pois sua residência abrigava milhares de livros. Mais tarde, incorporou a sua rotina, o "traiçoeiro computador" (NUNES, 2009, p. 91), que lhe possibilitou organizar melhor sua produção. Foi com essas condições mínimas, isolado do mundo, vivendo sob o intenso calor da cidade de Belém, que produziu sua imensa obra. Fez, desta forma, do escrever o seu modo de vida (NUNES, 2012a, p. 214).

Os inúmeros escritos que produziu - livros, artigos, ensaios, capítulos de livros - frutos de pesquisas que realizou no campo da filosofia e da literatura, constituem o seu principal legado, de valor inestimável e que vem sendo estudado por pesquisadores de todo o país e exterior. $\mathrm{E}$ será também, objeto de investigação de gerações futuras que venham a se interessar por temáticas relativas a essas áreas, as quais dedicou a maior parte de suas reflexões.

Mas, além de sua produção bibliográfica, há um outro legado, pouco evidenciado de Benedito Nunes, esse diz respeito a sua atuação como docente na Universidade Federal do Pará (UFPa.). Nesta instituição, se tornou referência obrigatória, não apenas pelos escritos que produziu, mas também, pela sua grande contribuição para o ensino da Filosofia, ao propor a criação de um curso de Filosofia e lutar para que as suas condições de oferta ocorressem dentro de um padrão de qualidade, bem como pela sua atuação como docente. Formou gerações de professores, que o sucederam no antigo Departamento de Filosofia e Ihes ensinou que para estudar e ensinar Filosofia bastava dedicação, um certo talento e modéstia intelectual.

No presente trabalho, nosso objetivo é prestar uma justa homenagem a Benedito Nunes, ao procurar evidenciar o seu papel como idealizador do curso de Filosofia da UFPa e seu empenho para que esse curso fosse desenvolvido com êxito. $E$ também, destacar a sua atuação enquanto professor do curso. Pretendemos mostrar que ele foi uma pessoa ímpar, extremamente dedicada ao curso e que serviu de exemplo a todos os seus alunos pela sua humildade e pelo seu esforço constante de arrebanhar novos philos para a filosofia.

\section{Benedito Nunes idealizador do Curso de Filosofia da UFPa}

O curso de Filosofia da UFPa foi criado em 1973, por meio da Resolução do n 169, de 22 de junho de 1973, do CONSEPE, mas só começou a funcionar, efetivamente, a partir de 1975, quando ocorreu o primeiro vestibular para Filosofia, entretanto, pouco se sabe da história do curso. Os registros são poucos, os documentos que existem sobre sua criação são os referentes a pareceres e resoluções que o aprovaram, mas a proposta com a exposição de motivos sobre a importância de sua criação, atas das unidades e instâncias as quais foi submetida à apreciação, 
se perderam. Temos apenas a memória e o testemunho de quem vivenciou os momentos, nos quais foi pensada uma proposta de criação de um curso de Filosofia na UFPa, e de quem, na qualidade de aluno e/ou professor como eu, vivenciou os primeiros anos de oferta do curso. É importante observar que naqueles anos duros de regime militar, era uma ousadia muito grande alguém pensar em criar um curso de Filosofia e, além disso, estudar Filosofia. O caminho da criação à consolidação do curso é permeado de percalços e dificuldades, que foram sendo superadas pouco a pouco, graças ao esforço do seu idealizador, Benedito Nunes.

Poderíamos dizer que o curso de Filosofia da UFPa foi a concretização de um sonho, que ele não conseguiu realizar, o de estudar Filosofia na Universidade Estadual de São Paulo (NUNES, 2012b, p. 201). E, como na época não existiam cursos de Filosofia em Belém, teve que optar pelo Direito. Mas nem por isso, se desviou de seu ideal, pois o que não pode estudar em um curso de Filosofia, aprendeu sozinho, como autodidata. E nenhum curso de Filosofia poderia lhe proporcionar o aprendizado e o patamar que conquistou em termos de conhecimento de Filosofia, por seus próprios esforços. Mas, se ele não realizou o seu projeto de cursar uma graduação em Filosofia, possibilitou que muitos tivessem essa oportunidade. Hoje a maior parte do corpo docente do curso é composta por seus ex-alunos. E é, justamente, porque hoje temos um curso de Filosofia na UFPa, consolidado, que não podemos esquecer aquele, que nos primeiros anos da década de 70, ousou pensar, que uma universidade para ser uma verdadeira universitas, precisava ter em seu âmbito, um curso de Filosofia, e essa pessoa foi Benedito Nunes.

Mas, o projeto de um curso de Filosofia na UFPa já se fazia presente na sua cabeça desde a existência da Faculdade de Filosofia Ciências e Letras, criada em 1955, que ironicamente trás em seu nome o termo filosofia, sem ter um curso de Filosofia em seu âmbito e formava professores de Filosofia para o ensino secundário. Situação, hoje considerada inconcebível, mas naquela época não era exigido à habilitação especifica para se ministrar a disciplina. Em seu discurso, pronunciado por ocasião do quinto aniversário da Faculdade de Filosofia, Benedito Nunes define como objetivo dessa Faculdade:

[...] o preparo de professores habilitados pelos seus conhecimentos e por uma formação didática adequada, a transmitir aquilo que aprenderam, servindo-se dos métodos mais eficazes, com economia de tempo e esforço. O professor, formado em qualquer curso, é um profissional que fará da História ou das Matemáticas, da Geografia ou da Filosofia a sua especialidade, dominando a disciplina que escolheu e dentro da qual se aperfeiçoou, com o fim de torná-la acessível aos estudantes de letras ou de ciências no curso secundário (NUNES, 2012c, p. 186).

Mas, acrescenta um outro objetivo que sintetiza o "sentido do labor intelectual" em uma Faculdade de Filosofia e que ele considera como uma "etapa dialética de maior e de mais completa integração dos conhecimentos e técnicas" que se adquire em seu âmbito. Trata-se da "elaboração da cultura, do espírito filosófico e, mais especialmente, do professor de Filosofia" (NUNES, 2012c, p. 186). Vista da perspectiva deste "estágio supremo" a Faculdade de Filosofia se define como uma "escola do pensamento e o veículo da cultura" (NUNES, 2012c, p. 186).

Nota-se que na cabeça de Benedito Nunes já havia a ideia de que a Faculdade de Filosofia deve ser uma escola de pensamento e, enquanto tal, é o espaço no qual se produz o professor de Filosofia e não o filósofo. Deixa claro este propósito quando afirma: “É obvio que a Faculdade de Filosofia não se destina a produzir filósofos, que não se improvisam nem se formam apenas estudando os programas do curso apropriado e tomando contato com as disciplinas filosóficas" (NUNES, 2012c, p.186-187). E considera que mesmo o professor de Filosofia, que seja "um expositor de sistemas, doutrinas e conceitos" precisa possuir um certo talento, certas "habilidades 
morais e intelectuais, que não se adquirem em qualquer curso regular disciplinado por rígidos programas" (NUNES, 2012c, p. 187).

Mas, a ideia de um curso de Filosofia precisava ser amadurecida, pois no espaço da Faculdade de Filosofia, no qual faltavam recursos que assegurassem a sua própria subsistência e cuja existência e função não eram bem compreendidas, chegando alguns a pensar que na Faculdade de Filosofia só se estudava Filosofia e a objetar que o Pará não precisa de filósofos, ali ainda não havia as condições necessárias para a criação de um curso de Filosofia (NUNES, 2012c, p. 196). Na verdade, as duas únicas disciplinas filosóficas, que se estudava nessa Faculdade, eram a Ética, ministrada pelo próprio Benedito Nunes para o Curso de Ciências sociais e a História da Filosofia, ministrada pelo Professor Carlos Coimbra para o Curso de Pedagogia (COIMBRA, 2011b, p. 208).

Posteriormente, com a reforma universitária e a criação do ciclo básico, que visava suprir as deficiências da formação intelectual do estudante que ingressava na Universidade, Benedito Nunes elaborou um projeto para a inclusão da disciplina Introdução à Filosofia no âmbito de todos os cursos da área de Ciências Humanas. Mas, ele tinha em mente um projeto mais ambicioso, pensava incluir tal disciplina na grade curricular de todos os cursos da UFPa, entretanto, esbarrou com algumas dificuldades para sua concretização (COIMBRA, 2011, p. 208). Um desses problemas foi a carência de professores graduados em Filosofia. O pequeno grupo de docentes, incumbido de assumir o magistério daquela disciplina, não possuía a formação filosófica adequada para ministrá-la. Conforme ressalta Gueiros:

Belém, não contava, à época, com graduados em Filosofia, de modo que nós, oriundos do Direito, da Pedagogia, da Teologia, precisávamos estudar intensamente o programa proposto num patamar adequado ao aluno iniciante e, simultaneamente, firmarnos como grupo aplicado ao aprofundamento indispensável dos estudos filosóficos (GUEIROS, 2011a, p. 203).

Um outro problema dizia respeito ao próprio programa da disciplina Introdução à Filosofia, que carecia de uma certa unidade em seus conteúdos e bibliografia (COIMBRA, 2011b, p. 208). Para superar essas dificuldades Benedito Nunes elaborou um único programa de Introdução à Filosofia, passando este a ser constituído por uma unidade introdutória na qual se tratava das acepções da palavra filosofia, distinções e relações entre filosofia e ciência e, em seguida, se abordava os problemas filosóficos: teoréticos, práticos e poéticos e as questões metafísicas, com os desdobramentos necessários para as áreas da Teoria do Conhecimento, da Lógica, da Ética, da Politica e da Metafisica. Propôs também, uma bibliografia básica, indicativa de textos a serem estudados em cada unidade. Tratava-se de um programa ambicioso, que pretendia abordar as diferentes áreas da Filosofia da perspectiva de seus problemas. Durante anos, todos os professores que ministravam tal disciplina adotaram esse programa ou o tomaram como referência.

Definido o conteúdo programático da disciplina, Benedito Nunes procurou solucionar os problemas decorrentes das limitações da formação filosófica dos docentes selecionados para ministrá-la. Nesse sentido, formou um grupo de estudo permanente. Este grupo se reunia à noite, fora do horário de expediente da UFPa, para aprofundar seus estudos de Filosofia sob sua orientação. Tratava-se de um curso de aperfeiçoamento em Filosofia e História da Filosofia. Ele indicava o filósofo e as obras a serem lidas por todos e assim, dentre outros, foram estudados Hegel, Husserl, Heidegger, Sartre, Foucault, Ricoeur (COIMBRA, 2011, p. 208). Foi no âmbito deste grupo de professores que ele plantou a ideia de criação de um curso de Filosofia na UFPa e, visando concretizá-la, deu continuidade a formação filosófica do grupo para que pu- 
desse assumir, as cadeiras de Lógica, Ética, Teoria do conhecimento, História da Filosofia e Filosofia Geral, disciplinas que iriam compor a grade curricular do novo curso.

Mais tarde, esse grupo coeso de professores que se dedicou arduamente e com seriedade ao estudo da Filosofia, passou a constituir o corpo docente do curso de Filosofia. A este respeito Gueiros esclarece:

Éramos seis naquele pequeno grupo, movidos por um encantamento peculiar comum aos que se encontram com a Filosofia e a atividade que lhe é correspondente [...]. A seriedade e a dedicação do grupo aos estudos possibilitaram, mais tarde a implantação do Curso de Filosofia na Universidade Federal do Pará (GUEIROS, 2011a, p. 203-204).

Os seis eram: o próprio Benedito Nunes, Armando Avellar, Carlos Coimbra, José Carlos Castro, Hidelberto Bitar, Terezinha Gueiros. A esse grupo vieram somar-se outros, na medida em que foram sendo realizados concursos na UFPa, nos quais Benedito Nunes estava sempre a frente procedendo a avaliação e seleção dos candidatos. Ele, era também, o líder do grupo de Filosofia e a quem competia fazer a distribuição das disciplinas entre os professores, conforme seus potenciais e interesses por determinada área da Filosofia.

O curso de Filosofia surge assim, com um pequeno grupo de professores, que não são graduados em Filosofia, mas que obtiveram sua formação filosófica à luz dos cursos de aperfeiçoamento de Benedito Nunes e tem a pretensão de formar licenciados plenos em Filosofia, sem futuro, diga-se de passagem, pois, naquela época, a Filosofia havia sido excluída dos currículos das escolas do antigo segundo grau ${ }^{1}$ pelo regime militar. É importante notar, que a proposta inicial do curso, não tinha a pretensão de formar bacharéis em Filosofia e, dessa forma, deixava de fora outros estudantes, que muito embora tivessem talento para o estudo da Filosofia não tinham interesse pelo magistério.

O currículo do curso foi organizado tendo por base o parecer n 277/62 do CFE que definia o "currículo mínimo" de Filosofia e na Resolução n 01/72, do CFE, que fixava o tempo de duração e carga horária das diferentes licenciaturas. Assim, em consonância com a legislação vigente na época, a estrutura curricular do curso era constituída das disciplinas obrigatórias do primeiro ciclo (ciclo básico), correspondentes à área de Filosofia e Ciências Humanas²; disciplinas do currículo mínimo e complementares obrigatórias, a saber:Teoria do conhecimento l e II, Lógica I, II e III, Filosofia geral I, II e III, História da Filosofia II, III e IV, Antropologia filosófica, Antropologia Cultural I, Teoria da história, Matemática I, Fundamentos de Matemática elementar I, Estudos de problemas brasileiros (EPB) I e II; disciplinas optativas e disciplinas da formação pedagógica, comuns a todas as licenciaturas ${ }^{3}$.

Mas, os desafios de Benedito Nunes, para a criação do Curso não se resumiram na elaboração da exposição de motivos, na organização do currículo, na seleção e preparação do quadro docente. Com a realização do primeiro vestibular, em 1975, que selecionou apenas 20 alunos para cursar a licenciatura em Filosofia de um total de 40 vagas ofertadas, surgiram outros problemas. Haviam as dificuldades dos alunos com o estudo da Filosofia; a carência de livros de Filosofia na biblioteca; o número reduzido de professores; a limitação de textos para as aulas, esses eram poucos, geralmente, datilografados a partir do livro do filósofo e/ou de Histórias da

\footnotetext{
1 O ensino de segundo grau corresponde hoje ao Ensino Médio.

${ }^{2}$ As disciplinas do primeiro ciclo da área de Ciências Humanas eram: Introdução à Filosofia, Introdução à Sociologia, Introdução à Economia, Introdução à Metodologia das Ciências sociais, Língua portuguesa e comunicação, Introdução à psicologia, História da Filosofia I, duas disciplinas optativas.

${ }^{3}$ As disciplinas da formação pedagógica eram as seguintes: Introdução à Educação, Psicologia da Educação, Estrutura e Funcionamento do ensino de $1^{\circ} \mathrm{Grau}$, Estrutura e Funcionamento do Ensino de $2^{\circ} \mathrm{Grau}$, Didática Geral e Prática de Ensino I e II.
} 
Filosofia; a ausência de um espaço adequado para a realização do estágio curricular em Filosofia, pois com salientei com o regime militar, que se instaurou no país, a Filosofia havia sido banida dos currículos das escolas de segundo grau, e seu lugar foi ocupado por Organização Social e Política Brasileira (OSPB) e Educação Moral e Cívica (EMC). Essas dificuldades não eram estranhas a Benedito Nunes, que envidou esforços para que fosse adquirido um acervo mínimo de Filosofia para a biblioteca, e, na qualidade de editor, para que as obras completas de Platão, cujos direitos autorais pela tradução haviam sido doados a UFPa, por Carlos Alberto Nunes, fossem publicadas pela editora dessa Universidade. Disponibilizava também, o acervo de sua biblioteca particular para seus alunos que não dispunham dos livros indicados na bibliografia das disciplinas que ministrava. Atitude generosa e louvável, naquela época que os únicos livros disponíveis para o aluno estudar Filosofia eram os da coleção "Os pensadores", editada pela Abril Cultural.

Benedito Nunes esteve à frente do movimento nacional pelo retorno da Filosofia aos currículos das escolas de ensino de segundo grau, que de certa forma viria sanar o problema do estágio supervisionado do curso de Filosofia, pois dada a ausência da Filosofia nos currículos dessas escolas, os alunos realizavam o estágio curricular em turmas das disciplinas de Educação Moral e Cívica, de Organização Social e Política Brasileira e, por vezes, de História. Elaborou, também, uma proposta de reintrodução da Filosofia nos currículos das escolas estaduais do Pará, na qual apresentou várias razões para o seu retorno e apontou o que ela poderia proporcionar em termos de mudança de "mentalidade instrumental e imediatista" dos estudantes (NUNES, 1986, p. 121).

A proposta procurava ressaltar também, a concepção de ensino da filosofia, que a norteava. Esse não devia ser visto como "transmissão pura e simples de determinada ordem de conhecimentos", mas sim seguindo o dito kantiano, "como um gênero de prática do pensamento a ser despertado" (NUNES, 1986, p. 121). Nesse sentido, o retorno da filosofia constituía uma forma de se "reinstilar no Curso Médio a potencialidade fecundante desse modo de pensar" (NUNES, 1986, p. 121) e não de se acrescentar aos currículos das escolas uma nova disciplina que viesse a suprir certas deficiências da formação dos estudantes do Ensino médio.

Benedito Nunes pensou ainda, em sua proposta, critérios para nortear a elaboração dos programas, que levavam em conta o caráter "propedêutico", "interrogativo"; "dialógico", "textual", "diversificado" e "gradual" do ensino da Filosofia (NUNES, 1986, p. 122-123). Com base nesses critérios propôs quatro programas diferenciados, que procuravam contemplar as diferentes modalidades e habilitações do ensino de segundo grau da época. Um primeiro, destinado à formação geral, era composto de um repertório de temáticas básicas, referentes à natureza da Filosofia e a reflexão crítica, a indagações sobre a natureza, a linguagem, a sociedade e a cultura, o conhecimento, a criação artística e a ciência. O segundo, para atender aos cursos de Eletrônica, Construção civil e Mecânica, cujos conteúdos visavam tratar de questões referentes à lógica, ao método científico, às ciências físico-matemáticas, à evidência, à probabilidade e à verdade, dentre outros temas. O terceiro, estava voltado para os cursos da área de saúde, e procurava dar ênfase às questões dessa área, tais como, a biologia como ciência, o domínio do orgânico, evolucionismo e teorias evolucionistas, a vida na escala de valores. E, por fim, o quarto, destinado aos cursos de Comércio, Administração, Crédito e Finanças, procurava abordar questões referentes à sociedade e trabalho, à moral, à liberdade e responsabilidade, à vida política e o Estado, ao humanismo e tecnologia. Observa-se na elaboração desses programas todo um compromisso de Benedito Nunes com o ensino da Filosofia e um cuidado para que a Filosofia pudesse ser significativa para cada área que fosse estudada, de modo a possibilitar o exercício da reflexão filosófica dos estudantes. 
Consoante à proposta de reinclusão da Filosofia, Benedito Nunes pensou um curso de treinamento para os licenciados em Filosofia visando à atualização da disciplina e a melhoria do desempenho didático no seu ensino. Esse curso foi pensado tendo em vista os programas propostos para aquele nível de ensino. Visava assim, um estudo "ordenado e sistemático" dos conteúdos programáticos, de modo a possibilitar a "aquisição de um primeiro nível de experiência teórico-prática" (NUNES, 1986, p. 125-126), que servisse de apoio a atuação competente dos docentes da disciplina.

Nesse sentido foi celebrado um convênio entre a UFPa e Secretaria de Estado de Educação do Pará (SEDUC), no qual as partes envolvidas definiram seus compromissos. A UFPa., através do seu Departamento de Filosofia, assumiu, dentre outros compromissos, o de ofertar, semestralmente, cursos de atualização tendo como foco os programas da disciplina Filosofia do ensino de segundo grau; a avaliação e revisão periódica dos mesmos; promover palestras e conferências sobre temáticas filosóficas e a publicação de textos de Filosofia destinados ao ensino da disciplina no ensino de segundo grau. E, a SEDUC, por sua vez, comprometeu-se a só admitir como docentes, os que frequentaram com aproveitamento os cursos de atualização; não modificar os conteúdos programáticos da disciplina Filosofia, sem prévia discussão com a Universidade e também permitir, quando fosse solicitado, o estágio de alunos do curso de licenciatura em Filosofia nas escolas de ensino de segundo grau (Convênio UFPa/SEDUC apud MONTEIRO, 2000, p. 139-140). Assim, com fruto desse convênio, se criou um campo de estágio, nas escolas estaduais, para os alunos do curso de Filosofia.

Podemos dizer que foram anos de dedicação de Benedito Nunes a esse "filho" que ele idealizou, viu crescer e muitas vezes manifestou seu descontentamento com os rumos que ele tomou, em avaliações severas que fez do curso, ao observar o desempenho dos alunos face aos critérios de avaliação que cada docente utilizava; a falta de definição de um nível de exigência mínimo no ensino das disciplinas; a imprecisão dos objetivos dos docentes, no que diz respeito aos programas das disciplinas que ministravam; a falta de diálogo entre eles sobre as suas leituras e as suas preocupações teóricas. Julgava que o curso havia perdido sua identidade, na medida em que cada professor procedia isoladamente e respondia por si mesmo e não pelo curso. Faltava, assim, ao curso, conforme ressalta Nunes, "o exercício de um ensino responsável, pelo intercâmbio interno, pela colaboração mútua entre nossas disciplinas gerando entre nós o liame comum do estudo e da reflexão, por onde passa a identidade própria do Curso de Filosofia" (NUNES, avaliação do curso de Filosofia s/d, p. 3). Considerava que só se poderia resgatar a identidade do curso e seu padrão de qualidade pela prática da atividade acadêmica, que ele resumiu nos seguintes termos: "informação, atualização, confrontação dialogante entre nós, convivência dialogal entre nós e os estudantes" (NUNES, avaliação do curso de Filosofia s/d, p. 3).

A preocupação de Benedito Nunes era tão grande com a identidade do curso e em elevar o seu nível de qualidade que chegou, inclusive, a propor, como meio de se superar as dificuldades enfrentadas, uma união dos docentes, em torno de um "compromisso moral e intelectual livremente assumido e que cada qual honraria como um princípio de ação comum, profissional, uma espécie de frente ética que [se] adotasse, em benefício da reviravolta qualitativa do nosso curso" (NUNES, avaliação do curso de Filosofia s/d, p. 3).

Observa-se, assim, que no que diz respeito ao curso de Filosofia, que se propôs a criar, Benedito Nunes sempre envidou esforços para que esse curso tivesse uma identidade própria e um padrão de qualidade, que não deixasse nada a dever, se comparado ao de outras grandes universidades brasileiras. 
Mas, a dedicação e o cuidado de Benedito Nunes com o Curso de Filosofia da UFPa não se manifestaram apenas, enquanto ele atuou como coordenador e líder do grupo de Filosofia, mas também, enquanto professor desse curso, o que iremos mostrar a seguir.

\section{Bendito Nunes, professor do curso Filosofia}

Benedito Nunes se considerava, antes de tudo, um professor (NUNES, 2012a, p. 214) e foi como tal, que dedicou muitos anos de sua vida ao ensino da Filosofia e a formação de novas gerações de professores de Filosofia, que hoje integram o corpo docente de várias instituições de ensino superior, inclusive da UFPa., e escolas de ensino médio.

Como professor do curso de Filosofia, assumiu o encargo de ministrar várias disciplinas, dado o seu notável saber. No geral, seus cursos se concentravam na área de História da Filosofia e Filosofia Geral. Era uma autoridade nas disciplinas que ministrava, não a autoridade arrogante, que se julga dotada de muitas verdades e as arrota aos ignorantes. Era portador da humildade e modéstia socrática, não ostentava um saber, sua humildade estava na profundidade de sua sabedoria. Sabia conduzir os alunos pelos caminhos da Fenomenologia de Husserl; pela Filosofia de Heidegger, da mesma forma que os conduzia pela Filosofia Antiga, Medieval, pela Patrística, pela Escolástica, pela Filosofia iluminista, para citar alguns assuntos de seus cursos. E muito embora, fosse especialista em determinados filósofos nunca teve a pretensão de dogmatizá-los ou de considerá-los superiores a outros. Tinha consciência de que o dogmatismo não se coaduna com a Filosofia e que qualquer atitude de "arrogância magisterial, qualquer pretensão à doutrina definitiva" é incompatível com a Filosofia (NUNES, 2012c, p. 192). Diz ele: "Não me limitei a sentar praça numa Filosofia determinada, ao som do clarim da especialidade" (NUNES, 2012 b, p. 204). Preferia assumir a atitude cética e indagativa. E era esta atitude que procurava ensinar a seus alunos:"a duvidar de tudo, a tudo interrogar adequadamente com conhecimento de causa" (NUNES, 2012b, p. 203-204).

Com suas aulas procurava provocar a admiração, no sentido grego de thaumatsein, que nos leva a busca do saber e concedia ao aluno, o direito de ser ouvido, de questionar, de pensar, naqueles tempos em que pensar era proibido. Suas atitudes como professor destoavam do autoritarismo de outros, que se viam como transmissores de sistemas e conceitos filosóficos, muitas vezes reproduções de manuais ou de Histórias da Filosofia, e para os quais uma simples pergunta de um aluno era vista como um incômodo, uma interrupção do seu pensamento ou da sua exposição. Situação difícil para o aluno, que tinha que ouvir e ficar calado, naqueles anos de aulas da década de 70, em salas calorentas, às 14 horas, nos pavilhões do ciclo básico da UFPa. Benedito Nunes, ao contrário, via o discurso do professor como dialógico, que requer não apenas a presença do outro, como também, uma correlação com ele (2012a, p. 214). Nesse sentido, considerava a palavra do professor como "a sua pedra de toque sob a abóboda do silêncio, onde outra palavra, a do ouvinte, pode ressoar em diálogo" (2012a, p. 214). Essa sua posição aberta ao diálogo possibilitava que o aluno expressasse suas dúvidas e questões. Ele próprio reconhece que essa sua atitude, como docente, foi fruto de um aprendizado: "Ensinei-me a jamais abordar um assunto de que não tivesse suficiente conhecimento, a ouvir o estudante, a ser por ele inquirido e confessar-lhe minha ignorância quando fosse o caso" (NUNES, 2012b, p. 203).

Via o ensino da Filosofia como sendo dialético e que deve por a razão em atividade de modo a desencadear o processo do pensamento, o que, no seu entender, não constitui "tarefa fácil e tão comum". Esse ensino deve ter como virtudes primeiras e fundamentais a inquietação e a insatisfação. E ter como regra o "não conformismo absoluto" e a "total independência" 
(NUNES, 2012b, p. 192). Tais ideias acerca do ensino da Filosofia pôs em prática em suas aulas. E muito embora não tenha feito nenhum curso de didática, e aprendido a ensinar a duras penas, como ele mesmo declarou em seu discurso "Quase um plano de aula" (NUNES, 2012b, p. 201), praticava uma didática própria à Filosofia, a da exposição dialogada, a de organizar os conteúdos das aulas expositivas em esquemas - verdadeiros roteiros de estudos - que eram fornecidos aos alunos, depois de datilografados no estêncil e reproduzidos no mimeógrafo. Nessa sua didática, estava presente não apenas a apresentação rigorosa e lúcida dos conteúdos, mas também, a abertura para o diálogo, para o questionamento, para a reflexão, bem como, uma orientação para o aluno iniciante na Filosofia, estudar sozinho através dos roteiros que fornecia. Qualidades, que se reputa, como sendo de uma boa aula de Filosofia.

É importante, evidenciar ainda, quanto à atuação de Benedito Nunes como professor, que nas disciplinas, ministradas por ele, não se faziam presentes apenas seus alunos regularmente matriculados, mas também, outros ouvintes - docentes, ex-alunos e discentes de outras áreas - interessados em seus cursos e ensinamentos, dado o aprofundamento e o teor de suas análises. E, que além das aulas ministradas na Universidade, promovia cursos em sua residência para grupos de alunos interessados em aprofundarem certas temáticas filosóficas. E, ademais, ali recebia alunos de Filosofia para orientá-los em suas leituras, momento em que ocorria um diálogo bastante instigante que lhes possibilitava novas reflexões.

\section{Considerações finais}

Benedito Nunes nos deixou um grande legado em termos de produção bibliográfica, que ainda precisa ser estudado e analisado em todas as suas dimensões e sutilezas de modo a se evidenciar suas contribuições para a Filosofia e Literatura, principais áreas, as quais dedicou suas pesquisas.

No que diz respeito as suas contribuições para o ensino da Filosofia criaram, no âmbito da UFPa, o primeiro curso de Filosofia do estado do Pará e se empenhou para manter a identidade e o padrão de qualidade do curso em tempos difíceis, em que estudar Filosofia era uma forma de resistência, face o regime militar que se instaurou no país. $E$, enquanto professor do curso foi o mestre exemplar, sabia conduzir suas aulas de uma forma dialogada, que possibilitava ao aluno o exercício da interrogação, da reflexão e da busca do saber. Seus cursos, além dos alunos matriculados, atraiam a atenção de vários ouvintes, interessados em seus ensinamentos.

Muito embora fosse dotado de profundos conhecimentos filosóficos, Benedito Nunes não se julgava portador de uma grande sabedoria, era humilde e modesto, se considerava um aprendiz. E, como ele próprio declarou, foi o que fez a vida toda "aprender a aprender" (NUNES, 2012b, p. 199). Era o que ensinava a seus alunos, a serem sempre aprendizes, ou melhor, amantes da sophia, já que a própria filosofia não se define pela posse de um saber, mas sim pela sua busca constante.

E, por fim é importante ressaltar, que se Benedito Nunes considerava que pouco ou nada devia a Universidade, porque esta não Ihe possibilitou as condições necessárias para realizar suas pesquisas e produzir seus livros, pois escrevia em sua residência, consultava o acervo de sua própria biblioteca (NUNES, 2012b, p. 203), nós não podemos dizer o mesmo com relação a sua pessoa. Ele nos deixou um curso, o seu exemplo de humildade e acima de tudo, sua Filosofia, presente nas inúmeras obras que escreveu, que estão disponíveis para serem pesquisadas e estudadas. E cabe enfatizar que o curso de Filosofia da UFPa sobreviveu durante muito tempo a sua sombra e, depois de sua aposentadoria, a duras penas teve que atingir sua maioridade e deixar de ser tutelado. 
Sua faina como pesquisador e seu trabalho como professor será sempre lembrado por todos aqueles que tiveram a oportunidade de conviver com ele, como eu, e de usufruir de seus cursos e reflexões bastante lúcidas e instigantes.

\section{Referências}

COIMBRA, C. "Na confluência que nos une numa só transa filosófico-poética”. In: CHAVES, L.S. (Org.). O amigo Bené: fazedor de rumos. Belém: SECULT, $2011 \mathrm{~b}$.

CONSELHO FEDERAL DE EDUCAÇÃO (CFE). Parecer no 277/62 do Conselho Federal de Educação (CFE).

CONSELHO FEDERAL DE EDUCAÇÃO (CFE). Resolução no 01/72, do Conselho Federal de Educação (CFE).

GUEIROS, T. M. “Éramos seis ....." In: CHAVES, L.S. (Org.). O amigo Bené: fazedor de rumos. Belém: SECULT, 2011 a.

MONTEIRO, M.N. Filosofia da Educação no Ensino Médio em Belém. Belém: E.F.S., 2000.

NUNES, B. "A filosofia nossa de cada dia". Entrevista concedida ao jornal Mão livre. In: Revista Asas da palavra: Revista do Curso de graduação em Letras e do Programa de Pós-graduação em Comunicação, Linguagem e Cultura da Universidade da Amazônia (UNAMA). v. 12, n. 25, 2009.

NUNES, B. "Avaliação do Curso de Filosofia" da Universidade Federal do Pará. Não publicada e sem data.

NUNES, B. “Discurso de agradecimento por ocasião da titulação de doutor honoris causa pela Universidade da Amazônia". In: PINHEIRO, V.S. Do Marajó ao arquivo: breve panorama da cultura no Pará. Belém: SECULT/Pa. e Ed. da UFPA, 2012a.

NUNES, B. “Discurso pronunciado da sessão comemorativa do quinto aniversário da Faculdade de Filosofia, Ciências e Letras da Universidade do Pará". In: PINHEIRO, V.S. (Org.). Do Marajó ao arquivo: breve panorama da cultura no Pará. Belém: SECULT/Pa.; Ed. UFPA, 2012c.

NUNES, B. "Proposta para o ensino de filosofia no segundo grau”. In: NIELSEN NETO, H. (Org.). Ensino de Filosofia. São Paulo: Sofia Editora; SEAF, p. 119-126, 1986.

NUNES, B. "Quase um plano de aula”. In: PINHEIRO, V.S. Do Marajó ao arquivo: breve panorama da cultura no Pará. Belém: SECULT/Pa; Ed.UFPA, 2012b.

Resolução do $n^{\circ} 169$, de 22 de junho de 1973 do CONSEP/UFPa.

Termo de convênio celebrado entre a Universidade Federal do Pará e a secretaria de Estado de Educação do Pará, em 10/12/1984. In: MONTEIRO, M.N. Filosofia da Educação no Ensino Médio em Belém. Belém: E.F.S., 2000. 


\section{Sobre a autora}

\section{Elizabeth Assis Dias}

Doutora em Filosofia pela Universidade Estadual de Campinas. É professora titular, em regime de dedicação exclusiva, da Universidade Federal do Pará, vinculada ao Programa de Pós-graduação em Filosofia e ao Curso de graduação em Filosofia. Desenvolve pesquisas na área de Filosofia da ciência e, também, sobre o lluminismo Francês.

Recebido em: 08.07.2021.

Received: 08.07.2021.

Aprovado em: 02.08.2021.

Approved: 02.08.2021. 